\title{
Em busca de experiências: o verdadeiro mochileiro é aquele que já passou por vários "perrengues".
}

\author{
Eduardo Cidade ${ }^{1}$
}

\section{Resumo}

O objetivo deste estudo é avaliar a função do sofrimento na elaboração da individualidade e da solidariedade. Alego que o sofrimento não é apenas uma condição necessária filosoficamente oriunda da fome, da sede, da doença, da velhice etc. É culturalmente valorizado, utilizado como parâmetro para a distribuição e o ordenamento de posições e bens culturais. Se, para Rousseau, o homem é dotado de amor-próprio e compaixão pelo outro, sobretudo mediante o reconhecimento do sofrimento alheio, então a valorização do "martírio" talvez seja uma construção "artificial" desta compaixão. Neste empenho, o planejamento seria salientar a importância exercida pelo sofrimento em contextos contemporâneos, questionando o caráter supostamente utilitarista da pós-modernidade. Em um trabalho de campo com mochileiros na China, busco identificar relações entre situações de sofrimento que legitimam o discurso do que faz "um verdadeiro mochileiro".

Palavras-chave: identidade, turismo, China, mochileiros, sofrimento.

\begin{abstract}
The aim of this study is to evaluate the role of suffering in the elaboration of individuality and solidarity. I claim that suffering is not only a philosophically necessary condition arising from famine, thirst, disease, aging etc. It is culturally valued, used as a parameter for the distribution of spatial positions and cultural goods. If, according to Rousseau, man is endowed with self-love and compassion for others, especially through the recognition of someone else's suffering, then the appreciation of "martyrdom" may be way towards building a somewhat "artificial" compassion. I plan to emphasize the importance exercised by suffering in contemporary contexts, questioning the supposedly utilitarian character of postmodernity. In a field-study with backpackers in China, I seek to identify relations with suffering that legitimates the discourse of what makes "a true backpacker".
\end{abstract}

Keywords: identity, tourism, China, backpackers, suffering.

${ }^{1}$ Mestrando no Programa de Pós-graduação em Ciências Sociais (PPCIS) da UERJ. 


\section{Introdução: por um tipo ideal do sofrimento?}

Dentre as configurações essenciais da condição humana, o sofrimento surge enquanto uma das forças motoras da civilização. Uma consideração a priori dirá que a cultura é construída a partir da tentativa humana de evitar o sofrimento. Seja pelo viés do pacto social ou por uma dominação original, o homem se submete e aquiesça perante as leis da sociedade para, na união, impedir as ameaças da fome, da sede e de demais potências hostis da natureza. Uma vez domadas, real ou hipoteticamente, as forças da natureza cedem para um desafio tão formidável quanto: a dominação do homem de si mesmo. O processo civilizador é construído na tentativa de apaziguar os homens da guerra, liberando-os, supostamente de vez, do sofrimento oriundo pela violência. No entanto, o princípio teleológico de felicidade e prazer na Terra é uma confabulação ocidental, não podendo ser prolongar a povos diversos. E o sofrimento pode se tornar em prazer, sendo um fim em si mesmo, sobretudo quando é visto como belo e um ideal mesmo de civilização. Ainda que fosse possível retirar o sofrimento da vida dos homens, não creio que seja algo desejável. É a construção mesma da vida humana e seu valor que são postos em jogo. A relação do homem com a ecologia determina certas práticas culturais, mas não é determinista quanto aos valores empregados num ideal de vida e organização de conduta. É possível que as percepções de sofrimento moldem o certo e o errado na construção da ordem do mundo. $\mathrm{O}$ objetivo desse artigo é investigar a valorização cultural do sofrimento, em uma espécie de "estética da ética" em um estudo de caso específico, a citar, mochileiros na China ${ }^{2}$. Sob esta perspectiva, lembro que os mochileiros estão, temporariamente, distantes de suas relações sociais ordinárias. Seus hábitos e comportamentos são oriundos do enraizamento moral, não de coerção social externa: embora esta última exista, de modo sutil, nos locais de sociabilidade característicos do mochileiro. Ainda assim, são frequentados sem nenhum tipo de obrigatoriedade.

\footnotetext{
${ }^{2}$ Quando o artigo foi escrito originalmente, em outubro de 2011, ainda não havia realizado o campo. Manterei as hipóteses inalteradas para, neste artigo, não confundir minhas intenções prévias com os resultados adquiridos ao longo da pesquisa efetuada entre dezembro de 2011 e março de 2012. Apenas por referência, também estive, neste período, em quatro países do sudeste asiático (Laos, Vietnã, Tailândia e Camboja), cujas expectativas revelaram distintas à experiência chinesa.
} 
Para pensar o sofrimento enquanto valorização cultural é preciso delimitar uma abordagem com possíveis rupturas teóricas da necessidade prática e materialista. Embora não seja factível desassociar princípios, afetos e interesses na teoria da ação social, minha intenção é pesquisar o sofrimento nos termos mais abstratos, quiçá supérfluos, possíveis. Quais procedimentos legitimam o hedonismo, o prazer e o ócio? Como funciona a ideia de merecimento e, para além do trabalho, como o princípio de causalidade do mérito justifica demais práticas sociais? E como separar a vontade da necessidade? Foi então que surgiu a ideia dos mochileiros; mas, antes, quero aprofundar um pouco mais as prerrogativas

O sofrimento é tradicionalmente abordado em seu aspecto físico, exatamente pelo viés da dor, da doença e demais debilidades corpóreas. Há, ademais, ilustres estudos sobre o sacrifício e a relação do homem com o sofrimento no âmbito religioso. Embora qualquer generalização seja perigosa, talvez seja seguro afirmar que o sacrifício é uma das poucas instituições sociais presente maciçamente em variadas culturas, ainda que sob uma forma simbólica, entrincheirada pelo processo civilizador. Para fora da esfera religiosa, o sacrifício e o sofrimento costumam se secularizar a partir do Renascimento sob a forma do trabalho como valor ético. Diz um ditado popular de que há certo prazer no sofrimento: até que ponto ascetismo e hedonismo se mesclam, surgindo um do outro num processo cíclico difícil de estabelecer a causa originária? Renuncia e recompensa são susceptíveis de metamorfosear em orgulho/ reconhecimento e culpabilidade/ vergonha respectivamente. O "sofrimento físico" seria o mais nítido encontrado entre os mochileiros, indicando peculiaridades deste tipo de viagem que supõe contenções econômicas em alimentação, alojamento e transporte. Portanto, mesmo a perspectiva do trabalho seria de difícil abordagem, por enquanto, sob o prisma do sofrimento - ainda mais quando a necessidade é imperativa, como falar de uma valorização cultural, enquanto algo teoricamente da ordem do supérfluo ${ }^{3}$ ?

Em outras palavras, mochileiros escolhem voluntariamente um estilo de vida menos confortável ao usufruído no país natal em situações cotidianas, ao contrário de um turista tradicional, no qual um dos principais atrativos da indústria do turismo é oferecer hospedagens e restauração luxuosas para este público. Uma das minhas hipóteses principais

\footnotetext{
${ }^{3}$ Por "supérfluo" não quero dizer desnecessário, à deriva, mas denoto uma ação derivada puramente do livrearbítrio, se é que isto é possível. Talvez o sentido fique mais claro adiante. Os mochileiros não são obrigados a viajar à China; muito menos viajar durante tanto tempo. É uma escolha deliberada.
} 
gira em torno de que a concepção de ócio está mais relacionada coma ausência de atividades tidas como desagradáveis do que coma falta total de ação. Alguém pode realizar muitos atos, mas se forem todos considerados prazerosos seja para o sujeito ou para o imaginário dos circundantes, essa pessoa é ociosa—mesmo que a gama de suas atividades seja mais ampla do que uma segunda pessoa, considerada "ocupada". A percepção dessa visão pejorativa, se a hipótese for confirmada, visaria apontar que existem mais razões do que a mera propensão ao consumismo capitalista que estimulam as pessoas a produzir, o que talvez não seja totalmente explicado pela ética protestante weberiana. Ainda que impulsionado pelo consumo, a apropriação de dado objeto precisa adquirir certa legitimidade frente aos demais atores sociais. Para tanto, torna-se uma atividade desejável mesmo para aqueles que teoricamente não precisam realizá-la, ao menos em termos pragmáticos. É uma necessidade subjetiva, enraizada no sujeito, mas oriunda da coação social como quase todas as necessidades. Na dicotomia entre esforço e ócio, o mochileiro encontra seu contraponto: o turista "clássico", aquele que, aos olhos do primeiro grupo, é julgado como preguiçoso, sem iniciativa e desinteressado pela novidade e a cultura local. A falta de obstáculos a superar, a busca pelo conforto e o pagamento por serviços que facilitam a experiência da viagem depreciam os turistas "clássicos" aos olhos do mochileiro, alguns culminando ao extremo de não querer ser "confundido" com um turista. De certa forma, parece que quanto "piores" forem os hotéis, restaurantes, trens e ônibus, mais legítima é a afirmação de que, de fato, se conhece o "Outro", o nativo do país visitado. O nativo em questão se trata do "homem médio", visto, do ponto de vista europeu ou norteamericano, como invariavelmente mais pobre. É provável que os mochileiros busquem meios de transportes desconfortáveis e restaurantes simples na tentativa de simular o estilo de vida acessível à maioria dos nativos. Será tal simulacro condizente com a realidade do chinês "médio"? Quais outras ações os mochileiros adotam e quais outras acusam os turistas de realizar ou não?

A ação humana é baseada em pós-conceitos de avaliações interligadas na noção de causa e consequência adquirida em experiências pretéritas. Ela é fatalmente subjetiva. Afinal, é baseada na experiência sensível e dela não se pode desprender-se das noções de Ética e Moral. Talvez exista uma ruptura na tentativa de conciliar o "certo lógico" com o

\footnotetext{
${ }^{4}$ No que consiste o estereotipo do turista "clássico" é algo a ser perguntando aos meus entrevistados.
} 
"certo ético", uma vez que, normalmente, o último é incorporado quase que automaticamente na agência do ator social, orientando para uma espécie de "estética da ética". Diante qualquer situação-problema complexa, é inevitável que uma ideologia seja pautada nos valores éticos e morais e, então, procura-se por algum raciocino lógico a fim de justificá-la. A subjetividade levará em conta ora uma tendência positivista ora pessimista, ora empírica ou racionalista. Nunca a "coisa em si" inteligível, mas naquilo que é conspícuo.

Sempre me chamou a atenção fenômenos considerados menores da vida cotidiana como o fato de, quase invariavelmente, são os artistas e músicos consagrados que desdenham inovações tecnológicas capazes de permitirem leigos a produzir efeitos semelhantes em programas de computador; são costumeiramente os intelectuais que se prostram, alegando banalização do conhecimento, contra veículos da indústria cultural; os atletas que buscam identificar efeitos colaterais em remédios e técnicas medicinais no aprimoramento do corpo etc. Trata-se de uma questão de legitimidade: o atalho "anula" o sofrimento, então não pode ser legítimo e reconhecido, é o sofrimento do processo de aquisição que legitima a reivindicação de dado bem ou privilégio-quase como se o sofrimento incorporasse o reconhecimento desejado no ser do agente. Não obstante, é crucial interrogar até que ponto pode-se transformar tal postulação numa máxima social. Ainda é impossível escapar da arbitrariedade do meu juízo de valor.

Considero a existência de dois níveis de percepção e interpretação do agente, um social, ou seja, como a sociedade julga, com maior ou menor unicidade, a ação do indivíduo. Inserindo-se nas estruturas estruturadas estruturantes do Pierre Bourdieu, é impossível dar conta de "tudo", mas talvez o seja do "todo". O todo depende do arranjo dos elementos. Por exemplo, uma das grandes surpresas do capitalismo tardio é que as culturas "tradicionais" não são inevitavelmente incompatíveis com ele, tampouco vulneráveis deste. Logo, se o mundo atual se diz utilitarista, termo cunhado por Stuart Mill, creio que ainda exista algo de "tradicional" envolto pelo pragmatismo contemporâneo. Por isso mesmo, argumenta Sahlins contra ideia convencional que a cultura é sui generis, um objeto dito superorgânico, independente dos sujeitos humanos que o atualizam ${ }^{5}$. Mesmo que use

\footnotetext{
${ }^{5}$ SAHLINS, Marshall. "Experiência Individual e Ordem Cultural”. In: Cultura na Prática. Rio de Janeiro, Editora UFRJ, 2004. Rio de Janeiro. O autor possui um interessante comentário sobre a dicotomia entre
} 
valores monetários para medir todos os tipos de bens e serviços, a sociedade ocidental ainda é dotada de outras lógicas inscritas nas intenções.

É extremamente recorrente entre mochileiros, conforme observei em viagens pretéritas, a busca por "autenticidade", de sair do "beaten track" turístico. O autêntico exige uma elaboração de conhecimento pessoal, de busca por experiências inéditas-apesar da improvável efetivação prática, a tentativa permanece. É uma aversão do que é fácil, do dado, como os serviços oferecidos pelas agências de viagens e indústria do turismo. Para ser um "verdadeiro" viajante e "ter" experiências autênticas, é preciso se esforçar.

De qualquer maneira, para se "ter" algo de modo legítimo, a ideia de sacrifício é imprescindível. É antagônica à noção capitalista sob a abordagem utilitarista e materialista, pois, se o que importa é o produto final, seus meios deveriam ser irrelevantes. Logo, o utilitarismo apresenta sua contradição "não útil”. As emoções dos atores anulam o pragmatismo teórico, consolidando, na prática, uma afirmação oposta do ideal conceitual. Se por utilitarismo, entende-se que o fim é irrelevante aos meios, ideias como "mérito", "esforço" e outras denotando "recompensas pelo sacrifício realizado" transportam aos meios uma importância talvez até maior que o próprio fim. Isso é, afinal, o rito de passagem, necessário para reafirmação da nova identidade.

Até que ponto os homens visam somente um fim utilitário, despreocupado com o meio para alcançá-lo? Devo lembrar que, para Simmel, a burocracia contemporânea tornase um fim em si mesmo. É a valorização do meio em prol do fim que pauto minha pesquisa. Ao longo deste estudo, elaborarei outras problemáticas com os mochileiros, mas é evidente na relação entre tempo e dinheiro e o antagonismo com a categoria "turista" que não é possível desconsiderar tais questões. Em um esquema micropolítico, os ideais de mochileiros e turistas podem divergir, mas ambos dialogam com situações de realidades parecidas no país de origem. A condição mochileiro ou turista dura um tempo determinado, findada a viagem, tanto um quanto o outro retomam atividades da vida cotidiana. A viagem é vivida enquanto caráter excepcional. Não se trata, portanto, de identidades permanentes, como religião, gênero e etnia. Se for possível fazer uma principal distinção prévia entre mochileiros e turistas, é que os primeiros possuem bastante tempo e pouco dinheiro

“individualismo utilitário" e “determinismo cultural”, porém, para efeitos desta dissertação, não me aprofundarei no assunto. Não obstante, reproduzo aqui uma pertinente citação utilizada no texto de Sahlins: "a utilidade domina o estudo da cultura porque domina a cultura que estuda" (A. M. Hocart). 
enquanto os segundos, vice-versa. Tempo e dinheiro são considerados bens necessários para realizar uma viagem, mas a primazia de um sobre o outro determina, justamente, quem "faz mochilão" e quem "faz turismo". Nota-se de antemão que um mochilão de longa duração pode exigir mais dinheiro que uma viagem curta de turista: para que sessenta dias custe menos que seis, o mochilão precisa ser bem econômico e/ ou o turismo, bem luxuoso E o próprio fato de dispor de mais tempo pode significar uma condição social mais alta do mochileiro do que a do turista, mas voltemos agora ao aparato teórico pelo qual me guio.

\section{A relatividade do sofrimento: o que faz um verdadeiro mochileiro?}

Por mais que transformações culturais provoquem reestruturas, prescindidas por eventos históricos como a reforma protestante e revolução industrial, ela não sobrepuja o ideal de sacrifício expiatório. Aliás, a própria palavra remonta ao "sagrado": o que não se deve infringir, inviolável. Entretanto, "sacrifício" não é sinônimo de "dor" no sentido físico, tampouco "sofrimento" é símbolo de "sacrifício". Existe uma tênue diferença entre o sofrimento necessário para a recompensa e o masoquismo. Alego, em linhas gerais, que a linha divisora é social, em relação intrínseca com as concepções do "útil” e do "inútil”. O sofrimento útil é sacrifício enquanto o inútil, masoquismo. Porém, como distinguir? Evento e estrutura não estão separados, mas articulados. Determinadas ações repercutem em uma estrutura, mas não a transformam como um "evento". O evento extraordinário não é uma ruptura, ainda que transforme - a ação extraordinária emerge na estrutura existente. $\mathrm{O}$ mesmo evento gera expressões subjetivas diferentes em contextos diversos. Um padrão de comportamento oriundo de um evento extraordinário se desenvolve precisamente do padrão de comportamento já existente. O evento não molda o comportamento, este se dá pela articulação com a estrutura determinante, Talvez se deva seguir por estas pistas para distinguir as concepções do sofrimento. É um limite da minha pesquisa, porque não terei acesso aos "turistas". Possivelmente, para estes, viajar sob as condições de certos mochileiros retira o sentido da própria viagem. Se for para "passar perrengue", melhor ficar em casa. Mas será que o objetivo de qualquer turismo, seja o mochilão ou o resort, é sempre o lazer? 
O oposto de "trabalho" não é "lazer". Lazer pode gerar mais "sofrimento" do que o próprio trabalho na acepção geral de profissão (jogar futebol com amigos é mais cansativo que passar um fax no escritório). O lazer não é necessariamente prazeroso (vide o famoso "tédio do domingo"). Acima de tudo, o lazer não apenas é moralmente aceito na contemporaneidade, mas necessário para o bem estar do indivíduo. Logo, ele é tão "útil" quanto o próprio trabalho. Portanto, por que o filho de um homem rico, ao completar 18 anos e ganhar um carro de valor $\$ \$$, não é tão valorizado, em termos éticos e morais, quanto um self-made man que, após muito trabalho e esforço, compra um carro de valor apenas \$? Do ponto de vista econômico, o rapaz é mais "útil" que o trabalhador: sem ele o pai não compraria o carro, e o valor de $\$ \$$ faz mais capital circular na economia do que o valor de somente \$. Acredito que a resposta seja o "ócio", visto como falta de "sofrimento". Diga-se de passagem, o turismo é mais recorrente entre pessoas mais velhas e o mochilão, das mais jovens. Quando um jovem faz turismo ao invés de mochilão, é costumeiro justificar a falta de tempo por conta de trabalho e demais responsabilidades, indiretamente classificando o mochileiro como "ocioso". Por outro lado, será que os mochileiros não revidam e pensam os turistas e, acima de tudo, aos que não viajam apesar de possuírem recursos para isso, como "ociosos" também?

"Ócio" tem sua etimologia no grego skolé: "escola": denotando criatividade, contemplação, ideias. Enfim, uma "atividade" heurística. Julgar o "ocioso" como "inútil" é sempre relativo ao contexto, pois o "inútil" absoluto é somente coerente na idéia do "Nada" absoluto. Ou seja, o próprio Kháos. Caos não é somente o início da "Criação", mas também o apocalipse. Pode-ser-ia pensar na pesquisa inicial de Lévi-Strauss, pautada nas instituições sociais, como o parentesco. A partir do Pensamento Selvagem, Lévi-Strauss buscou o inconsciente. O suposto do estruturalismo é que o Homem não convive com a ausência de Ordem. Como as diferentes sociedades ordenam, por mais díspares que sejam, são potencialmente traduzíveis. O mochileiro, por sua vez, acusa o turista de falta de criatividade, de intensa necessidade de ordem. Não há "conhecimento do local" se o roteiro da viagem não permite improviso, se é previamente determinada. Entretanto, é o ordenamento do turista que anula o "sofrimento" do qual o mochileiro se submete, oriundo da imprevisibilidade. $\mathrm{O}$ conforto do turista se traduz num contexto de alienação capitalista. 
Tal desordem, por outro lado, é evitada pelo turista, vista como masoquismo: por que viajar se é para passar por situações difíceis?

O que posso fazer por prazer pode ser um martírio a outrem e vice-versa. Como buscar por universalidade em algo que há de tão subjetivo? Diversos ritos de passagem tribais incitam processos dolorosos (como ser picado por formigas entre os ianomâmi ou perfurar os mamilos entre o sioux). O limiar entre a dor física e o sentimento de prestigio pode deixar a interpretação do gesto imprecisa. Talvez seja essa a lógica por trás do orgulho que o mochileiro sente pela "superação", do cansaço em passar três dias dentro do trem de Péquim ao Tibete ao invés de sacar o avião.

Mary Douglas, no capítulo Abominações do Levítico $^{6}$, realiza uma racionalização a posteriori. Qual é a lógica que estrutura tal ordenamento que o faz que seja com é? O modelo parte do consciente para alcançar o inconsciente. A pena de um condenado também é dolorosa, porém em um contexto drasticamente diverso do rito que visa conferir uma posição de maior privilégio ao agente. O que num caso é nítida penalidade é honra e mérito noutro, longe de ser visto como condenação, embora os processos constituintes possam ser quase tão dolorosos quanto.

A análise estrutural deve ser feita em relação à realidade, do contrário seria delírio. Só se pode comparar o que é comparável entre si: eis o problema, como saber exatamente o que é comparável? Para comparar é preciso conhecer a história das coisas. Ainda que o conceito de cultura seja unificador e errôneo, se trabalharmos como se tal não existisse, nenhuma interpretação seria possível ${ }^{7}$. Todos os povos desenvolveram estruturas simbólicas nos termos das quais as pessoas são percebidas exatamente como tais: não como simples membros sem adorno da raça humana, mas como representantes de certas categorias distintas de indivíduos ${ }^{8}$.

É a concordância entre as estruturas objetivas e as estruturas cognitivas, entre a conformação do ser e as formas do conhecer, entre o curso do mundo e as expectativas a esse respeito, que torna possível esta referência ao mundo que Husserl descrevia com o nome de atitude natural, ou de experiência dóxica-deixando, porém, de lembrar as

\footnotetext{
${ }^{6}$ Pureza e Perigo.

${ }^{7}$ WAGNER, Roy. A invenção da cultura. Cosacnaify, 2010.

${ }^{8}$ GEERTZ, Clifford. "Do ponto de vista dos nativos: a natureza do entendimento antropológico": In: $O$ Saber Local. Petrópolis, Vozes, 1997. Página 228.
} 
condições sociais de sua possibilidade. Essa experiência apreende o mundo social e suas arbitrárias divisões, a começar pela divisão socialmente construída entre os sexos, como naturais, evidentes, e adquire, assim, todo um reconhecimento de legitimação. É por não perceberem os mecanismos profundos, tais como os que fundamentam a concordância entre as estruturas cognitivas e as estruturas sociais, e, por tal, a experiência dóxica do mundo social (por exemplo, em nossas sociedades, a lógica reprodutora do sistema educacional), que pensadores de linhas filosóficas muito diferentes podem imputar todos os efeitos simbólicos de legitimação (ou de sociodicéia) a fatores que decorrem da ordem da representação mais ou menos consciente e intencional ("ideologia", “discurso" etc) $)^{9}$.

O suposto prestígio alcançando por um rito de passagem não é necessariamente oficializado, institucional. Suponhamos duas pessoas no Rio de Janeiro contemporâneo que almejam emagrecer. Após certo tempo $x$, ambas perderam cerca de dez quilos. Não há nenhuma regra burocrática estipulando como deve ser o método oficial para o emagrecimento. Não obstante, é possível que aquela que perdeu peso mediante certos "sacrifícios", como dietas, ou melhor, reeducação alimentar (o que denota um forte caráter disciplinar) e exercícios físicos regulares provavelmente receberá mais créditos e louvor do que a outra que simplesmente tomou medicamentos de tarja preta. Ainda que para a segunda pessoa o discurso seja dos possíveis malefícios do medicamento, suspeito que o fator realmente agravante seja um suposto merecimento, como se o remédio "pulasse uma etapa necessária para usufruir a conquista”, uma falta de legitimidade.

No caso acima, o empecilho que posso ter enquanto pesquisador é pré-julgar que fazer exercício é necessariamente menos prazeroso do que não fazê-lo e que as comidas da reeducação alimentar, menos prazerosas do que as demais. Há pessoas que deveras desfrutam desse estilo de vida, embora eu julgue difícil compreender que elas o façam sem visar o fim estético acima de tudo, sendo o discurso da saúde apenas um método "menos fútil” para legitimá-lo, justificá-lo. Por outro lado, no caso dos mochileiros, considero-me um "estabelecido" neste grupo, podendo ser influenciado positivamente pelo discurso. Diante o Outro, a tentativa é não impor meus próprios juízos de valor para identificar seu

\footnotetext{
${ }^{9}$ BORDIEU, Pierre. A dominação masculina. Cap. I. Uma Imagem Ampliada. Rio de Janeiro, Bertrand Brasil, 2005.
}

INTRATEXTOS, Rio de Janeiro, Número Especial 03, pp.1-16, 2012. 
hupokeimenon-literally, that which stands or is placed underneath, the material of which things are made ${ }^{10}$.

Para Amélie Oksenberg, subjetividade consiste em seis aspectos pilares.

Our history reveals several distinctive strands in conceptions of subjectivity: it was constituted as a (1) first-person, (2) individuated, (3) self-referential, (4) authorative veridical report (or expression) of na (5) ocurrent (6) mental state (sensation, emotion, thought) ${ }^{11}$.

O discurso não é reprodução da realidade. O discurso age, produz e é produtor da realidade, dão formas à experiência. Se os homens representam as coisas como reais, elas são reais em sua consequência. Não se pune o crime atualmente, mas o criminoso, fazendo que as pessoas sejam catalogadas entre as que merecem ou não uma dádiva especifica. É um pensamento pensando na individualidade em relação à totalidade; o que é produção de subjetividade. O ceticismo surge quando determinada forma de ver o mundo entra em crise por alguma razão, como uma falência da gramática do ordinário. Essa fragilidade afeta o sentimento de segurança ontológica. A ordem simbólica que dá sentido ao mundo é frágil (Giddens), sobretudo diante mega eventos. As palavras podem ser distanciadas do seu contexto de origem, naturalmente situacionais na dialética fala e contexto.

\section{Considerações sobre a experiência e o desejo de conhecimento}

Segundo a razão instrumental de Horkheimer, o trabalho é uma forma de dominar da Natureza independente da época, o que pressupõe uma relação de dominação entre os homens, e entre o indivíduo e sua natureza subjetiva, seus instintos e desejos. Para esse domínio e essa auto-repressão são necessários cálculos de meios e fins. O motivo para fazer tantas menções ao trabalho deve ficar claro agora. Alego que situações de prazer, como uma viagem, precisam de certa justificativa de merecimento. $\mathrm{O}$ turista pode justificar seu conforto pelo trabalho árduo realizado no país de origem. $\mathrm{O}$ mochileiro transforma a própria viagem em "trabalhosa". Manter uma viagem longa necessita disciplina, uma vez

\footnotetext{
${ }^{10}$ RORTY, Amélie Oksenberg. "The vanishing subject: the many faces of subjectivity". In: BIEHL, João ET AL (orgs). Subjectivity: ethnographic investigations. Berkely, University of California Press, 2007, página 35. ${ }^{11}$ IDEM, página 44.
}

INTRATEXTOS, Rio de Janeiro, Número Especial 03, pp.1-16, 2012. 
que o dinheiro diário é limitado e os improvisos se multiplicam. Essa adaptação ao improviso com meios limitados é evidentemente variável e o prestígio deriva da maior habilidade de lidar com possíveis adversidades. Tal prestígio é sutil: para quem ele surte efeitos? Passar fome por falta de dinheiro, encarar dias dentro do ônibus por ser mais barato que um avião, dormir na casa de desconhecidos, na praça pública, na ferroviária etc são sinais de experiência, mas qual o limite para não se tornar excessivo? Quando o excessivo faz do mochilão não valer a pena? Quando se trata de uma atitude masoquista, de vontade de sofrer, ou seja, a negação desta vontade que naturaliza e transforma o supérfluo/ excesso em necessário?

A rigor, ninguém mais poderia ainda fundamentar de maneira racional os fins em si mesmos. Eles se confundem cada vez mais com meras preferências. No entanto, somente nessa inconstância característica das sociedades industriais modernas a racionalidade instrumental ganha predominância, como se ganhasse autonomia em relação aos indivíduos. Só o que é útil ganha o status de racional para a maioria das pessoas nessas sociedades, enquanto os fins podem variar conforme a situação pessoal.

Entrementes, não há sociedade sem dispositivo de poder. A disciplina é um ato de auto-punição. $O$ controle significa a substituição da luta inconsciente pela intenção consciente. $\mathrm{O}$ "desencaixe" para Giddens é uma sensação como se o tempo transcorresse mais rápido. Isto gera insegurança ontológica vide a flexibilidade gerar ansiedade existencial. O Indivíduo é egocêntrico, mas sem centro.

Nesta perspectiva, há um pressuposto de interioridade, especificidade e autenticidade do self para sempre vedada ao antropólogo, sobretudo em relações tão pessoais quanto ao que agrada e desagrada, entre prazer e sofrimento. Os meios que justificam os fins para uns não o fazem para outros, sejam pelas sensações provocadas ou juízos morais. Como saber se existe uma razão mais "profunda" para uma ação, como se aquilo que é aparente fosse tão somente ilusório? Ou melhor, em termos do Richard Sennett: as ficções que negam a luta individual pelo poder ou o conflito mútuo servem para fortalecer a posição dos que estão em cima ${ }^{12}$.

\footnotetext{
${ }^{12}$ SENNETT, Richard. A corrosão do caráter: as conseqüências pessoais do trabalho no novo capitalismo. Rio de Janeiro, Record, 2003.
} 
Entre turistas e mochileiros, os últimos costumam insinuar que o "excesso" de conforto e ordenamento, aliados ao tempo demasiado curto, faz com que os primeiros tenham bem-estar do corpo ao preço da alienação da "alma". É como se somente o corpo se deslocasse de país/ cidade. As privações de conforto, gerando sofrimento do corpo, providenciam a imersão "da alma". Pode-se, então, vivenciar a cultura local "verdadeiramente". O conforto é antítese da experiência nativa, o turista se coloca num patamar social acima do nativo, o que anula a possibilidade de conhecimento. Evidentemente, isto somente pelo pressuposto do "nativo médio", pois é sempre possível interagir com os nativos abastados. Depende, justamente, dos locais de preferência a circular e os objetivos da viagem. Entretanto, há sempre o risco do "excesso", de fazer "guerra demais ${ }^{13}$ ". Mochileiros mais experientes costumam narrar suas peripécias aos menos experientes num tom relativamente paternal, como em programas de televisão com atores em situações perigosas estampando a mensagem: somos profissionais, não tentem reproduzir os feitos em casa. Esse discurso é ao mesmo tempo preventivo, visando o bemestar alheio, e também uma forma de segregar o prestígio: é perigoso e não recomendo aos outros, mas eu já fiz isso. Certas peripécias são reservadas aos "verdadeiros" mochileiros, mas qual seria então o processo ritualístico da iniciação? Qual o delineador que faz um inexperiente se tornar iniciado?

Ademais, essas adversidades denotam uma separação temporal. Os erros acontecem pela falta de experiência e planejamento, são tão mais legítimos quanto menos recursos o agente dispõe, ressaltando o caráter aventureiro. Certos erros são permitidos nos "primeiros mochilões", a recorrência identificando falta de aprendizagem. Ou seja, se as maiores adversidades ocorrem quando ainda não se é um iniciado, são justamente elas o rito de passagem. Uma vez superadas, torna-se um "verdadeiro mochileiro", experiente o suficiente para preveni-las. Como manter, portanto, a dimensão da aventura? Radicalizando ainda mais as viagens, com menos recursos/mais tempo nos lugares? E o processo de envelhecimento para este público? Mochileiros são costumeiramente representados jovens. Nestas condições, a pobreza "voluntária", que jamais se confunde com a involuntária, é aceitável. O mesmo serve para as pessoas consideradas mais velhas?

\footnotetext{
${ }^{13}$ Mochileiros costumam se denominar "guerreiros", que "realmente conhecem a cultura local". A confusão com o turista pode ser ofensiva. É curioso, mas já escutei diversas vezes o protesto: I am not a tourist!
} 
Para Foucault, o discurso que pretensamente libera é repressor. Afinal, de quem é a verdade? Se a ideologia é falsa, então qual é a consciência verdadeira? É um pensamento evolutivo. Achamos que nos liberamos quando no fundo nos reprimimos. Se retirarmos o "aquilo" que nos reprime, surge logo outro "aquilo" para punição.

Não sei até que ponto é válido encarar prazer como liberdade e sofrimento como repressão. O sofrimento pode ser recompensador. Insisto que este é o principal dilema de minha pesquisa. $\mathrm{O}$ que é martírio para mim pode ser agradável para o outro. $\mathrm{O}$ que é válido se sacrificar para conseguir algo posteriormente ou mesmo enquanto fim em si mesmo para os sujeitos muda, embora, creio, em escalas menores dentro de uma mesma sociedade do que em relação ao Outro geograficamente distante, em outro locus.

Indivíduos são sujeitos constituídos por multiplicidades, com posições em discursos e práticas abrangentes muitas das vezes contraditórias e conflitantes. O indivíduo não tem uma postura "única", no sentido aristotélico da dialética não-contraditória. O processo criador de subjetividade não se esgota, fazendo com que o self adquira posições diferentes e atribuía significados antagônicos para os mesmos significantes através do tempo, conforme variações de poder e ideologia. O valor de uma teoria do sujeito é providenciar um meio para compreender como um self complexamente constituído se identifica com e/ ou e transforma várias posições subjetivas disponíveis dentro de um contexto particularsimultaneamente social, cultural, econômico e político ${ }^{14}$.

Antropólogos pós-modernos são objetos transformados em sujeito-que-fala. A Subjetividade não é Representação, a produção desta é constante, é algo implicado. Não é possível demonstrar o ponto de vista do nativo mediante o autor. O antropólogo é sempre objeto de estudo. Forma e conteúdo não se separam na narrativa. O paradigma do texto antropológico tem a ver com a interpretação, não mais na produção e sim na representação. O que me autoriza enquanto intelectual deter uma verdade superior à verdade daquele que a proferiu? Tentar fazer Antropologia não é se colocar como alguém com o ponto de vista do nativo, mas como alguém capaz de compreender o Outro. No meu trabalho, o nativo é um transeunte, tão difuso quanto o antropólogo. Mas não são os mochileiros antropólogos em potencial? Finalizo esse esboço com uma piada que escutei certa vez de um mochileiro

\footnotetext{
${ }^{14}$ MOORE, Henrietta. The subject of anthropology. Cap. 2 A genealogy of the anthropological subject. Cambridge, Polity Press, 2007. Adaptação livre do texto em inglês.
} 
"iniciado": a diferença entre o mochileiro e o turista é que, nas fotos, o primeiro está em vários lugares com a mesma roupa. O segundo está no mesmo lugar com roupas diferentes.

\section{Referências bibliográficas:}

MOORE, Henrietta. The subject of anthropology. Cap. 2 A genealogy of the anthropological subject. Cambridge, Polity Press, 2007.

RORTY, Amélie Oksenberg. "The vanishing subject: the many faces of subjectivity". In: BIEHL, João ET AL (orgs). Subjectivity: ethnographic investigations. Berkely, University of California Press, 2007.

SENNETT, Richard. A corrosão do caráter: as conseqüências pessoais do trabalho no novo capitalismo. Rio de Janeiro, Record, 2003

WAGNER, Roy. A invenção da cultura. Cosacnaify, 2010.

GEERTZ, Clifford. "Do ponto de vista dos nativos: a natureza do entendimento antropológico": In: O Saber Local. Petrópolis, Vozes, 1997

SAHLINS, Marshall. "Experiência Individual e Ordem Cultural”. In: Cultura na Prática. Rio de Janeiro, Editora UFRJ, 2004.

Durkheim, Émile. Da Divisão Social do Trabalho. Tradução: Eduardo Brandão. Martins Fontes, 2010

Durkheim, Émile. As formas elementares da vida religiosa. São Paulo, Martins Frontes, 2003.

SAHLINS, Marshall. Cultura na Prática. Rio de Janeiro, editora da UFRJ, 2004.

GIRARD, René. A violência e o sagrado. São Paulo, Paz e Terra, 2008.

BORDIEU, Pierre. A Distinção: crítica social do julgamento. São Paulo, Editora da Universidade de São Paulo, 2005.

WEBER, Max. Economia e Sociedade I. Brasília, UNB, 1991. 
$=$

-- Para o estudo, serão consultados sites e guias de viagem do O Viajante, Lonely Planet e Le Guide du Routard. Para contrapor o mochileiro com o turista, revistas de viagens também serão utilizadas. 